\title{
Microwave Assisted Synthesis and Characterization of Silver Nanoparticles Using Ocimum basilicum and its Anti-Inflammatory Activity against Human Blood Cells
}

\author{
P. Anitha ${ }^{1}$, P. Sakthivel ${ }^{2 *}$ \\ ${ }^{1}$ Assistant Professor, Department of Physics, Roever College of Engineering and Technology, Perambalur, Tamilnadu, India \\ ${ }^{2 *}$ Associate Professor, Department of Physics, Urumu Dhanalakshmi College, Trichy, Tamilnadu, India
}

\begin{abstract}
The present investigation was to synthesis the nanoparticles by using the medicinal plant Ocimum basilicum leaf extract and silver nitrate solution. The synthesized silver nanoparticles were analyzed by UV Spectroscopy (UV-Vis), Transmission Electron Microscopy (TEM), X-ray diffraction spectroscopy (XRD) and Fourier transform infrared spectroscopy (FTIR). The particle is found to have an average size of $14.6 \mathrm{~nm} \& 13.8 \mathrm{~nm}$ by XRD and TEM analysis respectively. The silver nanoparticles were synthesized by microwave assisted method, which was found to yield nanoparticles rapidly and easily. Further, these nanoparticles were found to exhibit AgNPs, which may also be efficiently employed in Anti-inflammatory activity of pharmaceutical research to obtain better result of plant as shown by our study. The anti-inflammatory activity of silver nanoparticles was tested and confirmed against human blood cells. Hence, the present research aims to open new avenues for the improvement of medicinal uses with the synthesis of silver nanoparticles by using Ocimum basilicum leaf extract for various ailments and to bring the anti-inflammatory medicinal plant to the scientist's notice, to educate awareness and add values to the resource.
\end{abstract}

Keywords: silver nanoparticles, Ocimum basilicum, TEM, XRD, FTIR, anti-inflammatory etc.,

\section{Introduction}

Nano structured materials have been fascinating in recent years since they show valuable and unusual remarkable properties, compared to conventional polycrystalline materials. Nanoparticles play an important role in all fields. In medical field it is used to treat skin cancer and reduce bleeding in trauma patients ${ }^{\mathbf{1}}$.Plant extracts are rich sources of secondary metabolites. Most of the extracts contain several metabolites that can easily reduce silver nitrate to silver nanoparticles. Ocimum basilicum (L.) is also known as sweet basil and King of spices. It is a popular Chinese medicinal herb of the family Labiatae ${ }^{2}$.Nanotechnology is rapidly growing technology, which holds a huge promise for the design and development of many types of novel products with its potential medical applications on early disease detection, treatment, and prevention. Nanoparticles produced and utilized in a wide range of commercial products throughout the world. The field of nanotechnology is an active area of research.

Nanoparticles exhibit new or improved properties based on specific characteristics such as size $(100 \mathrm{~nm})$, distribution and morphology. Nanotechnology is mainly concerned with synthesis of nanoparticles of variable sizes, shapes, chemical compositions and controlled dispersity and their potential use for human benefits ${ }^{3}$. In recent years, noble metal nanoparticles have been the subject of focused research due to their unique optical, electronic, mechanical, magnetic, and chemical properties that are significantly different from those of bulk materials ${ }^{4}$. Ocimum basilicum(Sweet basil) is one of the well-known and valuble medicinal plant and its extracts have been used to treat headaches, cough, diarrhea, warts, constipation, kidney mal-functions and microbial infections ${ }^{\mathbf{5} 6}$ and its Aglycones found to have antioxidant capacity ${ }^{7}$ Ethanol extracts of O.basilicum decrease cholesterol and lipid accumulation in human macrophages ${ }^{8}$. The silver and silver nanoparticles have been widely used in medical industry as topical ointments to prevent infection against burn and open wounds ${ }^{9}$. Therefore the present investigation was made to synthesis silver nanoparticle by using the leaf extract of O.basilicum to find their antiinflammatory activity of the plant.

Nanotechnology is an active area of research with tremendous applications for society, industry and medicine. The non-polluting nanotechnologies have revolutionized the production of nanomaterials as environmentally safe products. Several chemicals used in the chemical and physical synthesis of nanoparticles are toxic which leads to environmental pollution ${ }^{\mathbf{1 0}}$. Therefore biological sources can be an alternative for the synthesis of nanoparticles 11-13. Plants are the richest bio resources of drugs in traditional and modern medicine ${ }^{\mathbf{1 4}}$. Silver nanoparticles have wide range of applications such as catalysis ${ }^{\mathbf{1 5}}$, drug delivery ${ }^{\mathbf{1 6}}$, biosensing ${ }^{17,18}$ and optics ${ }^{19}$,were suggested as possible ecofriendly alternatives to chemical and physical methods. Ocimum basilicum (Lamenaceae) is a well known aromatic and medicinal plant, which attracted great attention in the ancient system of Indian medicine for its use in various ailments such as muscle cramps, pain, insecticidal, antiulcer, anti- inflammatory, diabetes and respiratory tract problems $^{\mathbf{2 0 - 2 4}}$. Traditionally, the essential oil of Ocimum basilicum was used as anti-inflammatory, antiseptic, and gastrointesinal protective medicine ${ }^{\mathbf{2 5 , 2 6}}$. Recently, microwave heating has been explored as a promising technique for nanoparticle synthesis. In the present study, we first report the reduction of silver ions using aqueous Ocimum 


\section{International Journal of Science and Research (IJSR) \\ ISSN (Online): 2319-7064 \\ Index Copernicus Value (2013): 6.14 | Impact Factor (2014): 5.611}

basilicum leaf extract under microwave irradiation for facile and fast phytosynthesis of silver nanoparticles (AgNPs). To the best of our knowledge, no reports pertaining to a microwave method by using Ocimum basilicum leaf extract are yet available. The anti-inflammatory property of silver nanoparticles was also investigated.

\section{Materials and Methods \\ Collection of leaf}

Fresh leaf of Ocimum basilicum were collected from Trichy, during the month of May and identified by Dr.John Britto, Director, Rabinat Herbarium and Center for Molecular Systematics, St.Joseph's College, Trichirappalli-2, Tamilnadu, India. (Plant authentication no: PN007)

\section{Preparation of Leaf Extract}

The fresh and young leaf sample of Ocimum basilicum was collected and washed thoroughly with sterile double distilled water (DDW). Twenty gram of sterilized leaf samples were taken and cut into small pieces. Finely cut leaves were placed in a $500 \mathrm{ml}$ Erlenmeyer flask containing $100 \mathrm{ml}$ of sterile DDW. After that the mixture was boiled for 5 minutes and filtered. The extract was stored in $4{ }^{\circ} \mathrm{C}$.

\section{Synthesis of Silver Nanoparticles}

Silver nitrate was used as precursor in the synthesis of silver nanoparticles. $100 \mathrm{ml}$ of Ocimum basilicum leaf extract was added to $100 \mathrm{ml}$ of $0.1 \mathrm{~N} \mathrm{AgNO}_{3}$ aqueous solution in conical flask of $250 \mathrm{ml}$ content at room temperature. The flask was thereafter put into shaker $(100 \mathrm{rpm})$ at $50^{\circ} \mathrm{C}$ and reaction was carried out for a period of $12 \mathrm{hrs}$. Then the mixture is kept in microwave oven for exposure of heat. The mixture was completely dried after a period of 20 minutes and hence nanoparticles in form of powders were obtained.

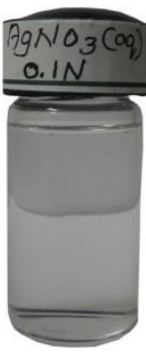

$\mathbf{A}$

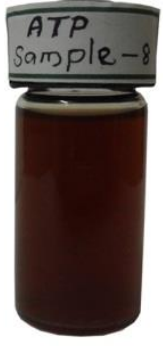

$\mathbf{B}$

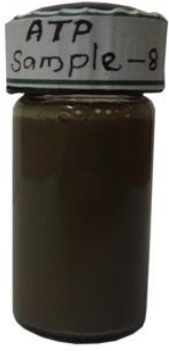

$\mathbf{C}$

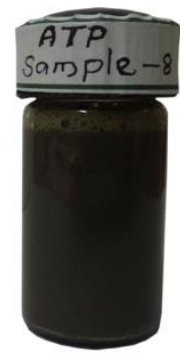

D

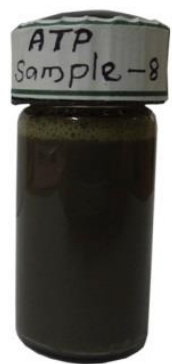

E

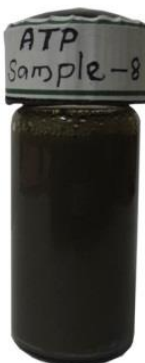

F

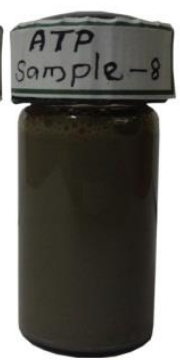

$\mathbf{G}$

Figure 1: Optical photograph of Ocimum basilicum A- $0.1 \mathrm{~N} \mathrm{AgNO}_{3}$ solution B- Leaf extract C- Leaf extract + AgNO ${ }_{3}$ $D$ - Leaf extract $+\mathrm{AgNO}_{3}\left(\right.$ After 30mins) E- Leaf extract $+\mathrm{AgNO}_{3}($ After $1 \mathrm{hr}) \mathrm{F}$ - Leaf extract $+\mathrm{AgNO}_{3}(\mathrm{After} 2 \mathrm{hrs})$ G- Leaf extract $+\mathrm{AgNO}_{3}($ After $24 \mathrm{hrs})$

\section{UV-Visible Spectroscopy Analysis}

The colour change in reaction mixture (metal ion solution + leaf extract) was recorded through visual observation. The bio reduction of silver ions in aqueous solution was monitored by periodic sampling of solid and subsequently measuring UV-visible spectra of the solid sample. UVvisible spectra of sample were monitored as a function of time. The UV-visible spectroscopy investigations were carried out using PERKIN ELMER (Lambda 35 model) spectrometer in the range of $190 \mathrm{~nm}$ to $1100 \mathrm{~nm}$.

\section{FT-IR Measurement}

The Fourier transform infrared (FTIR) investigations were carried out using PERKIN ELMER (Spectrum RXI) spectrometer in the range of $400 \mathrm{~cm}^{-1}$ to $4000 \mathrm{~cm}^{-1}$. The functional groups were identified using the peak assignments.

\section{XRD Measurement}

The sample was drop- coated onto Nickel plate by just dropping a small amount of sample on the plate, then it is allowed to dry and finally thick coat of sample was prepared. The particle size and nature of the silver nanoparticle was determined using X-ray diffraction (XRD). This was carried out using Rigaku miniflex-3 model with $30 \mathrm{kv}, 30 \mathrm{~mA}$ with $\mathrm{Cuk} \alpha$ radians at $2 \theta$ angle.

\section{TEM Analysis}

Sample is dispersed with acetone and exposed in ultrasonics for 5 minutes. Take a drop of a solution from the sample and drops it on the grid, leave until it dries. After drying the sample is inserted into TEM instrument using model Tecnai T20Making in FEI, Netherlands operating at $200 \mathrm{KeV}$ Tungsten Filament.

\section{Anti-Inflammatory Activity}

The human red blood cell (HRBC) membrane stabilization method

The method as prescribed (Gopalkrishnan et al., 2009; Sakat et al., 2010) was adopted with some modifications. The blood was collected from healthy human volunteer who had not taken any NSAIDS for 2 weeks prior to the experiment and mixed with equal volume of Alsever solution $(2 \%$ dextrose, $0.8 \%$ sodium citrate, $0.5 \%$ citric acid and $0.42 \%$ $\mathrm{NaCl}$ ) and centrifuged at 3,000 rpm. The packed cells were washed with isosaline and a $10 \%$ suspension was made. Various concentrations of extracts were prepared in $\mathrm{mg} / \mathrm{ml}$ using distilled water and to each concentration, $1 \mathrm{ml}$ of phosphate buffer, $2 \mathrm{ml}$ hypo saline and $0.5 \mathrm{ml}$ of HRBC suspension were added. It was incubated at $37^{\circ} \mathrm{C}$ for 30 minutes and centrifuged at 3,000 rpm for 20 minutes and the hemoglobin content of the supernatant solution was estimated spectrophotometrically at $560 \mathrm{~nm}$. Diclofenac $(100 \mathrm{Jg} / \mathrm{ml})$ was used as reference standard and a control 


\section{International Journal of Science and Research (IJSR) \\ ISSN (Online): 2319-7064}

Index Copernicus Value (2013): 6.14 | Impact Factor (2014): 5.611

was prepared by omitting the extracts. The experiments were performed in triplicates and mean values of the three were considered. The percentage (\%) of HRBC membrane stabilization or protection calculated using the following formula,

\section{Percentage of Protection $(\%)=$}

\section{(100- OD of drug treated sample/OD of Control) X 100}

\section{Albumin Denaturation Method}

The method as prescribed (Sakat et al., 2010) was followed with modifications. The reaction mixture was consisting of test extracts and $1 \%$ solution of bovine albumin fraction. $\mathrm{pH}$ of the reaction mixture was adjusted using small amount of
$\mathrm{HCl}$. The sample extracts were incubated at $37^{\circ} \mathrm{C}$ for 20 minutes and then heated to $51^{\circ} \mathrm{C}$ for 20 minutes. After cooling the samples the turbidity was measured spectrophotometrically at $660 \mathrm{~nm}$. Diclofenac sodium was taken as a standard drug. The experiment was performed in triplicates and the mean value of the three was considered. Percent inhibition of protein denaturation was calculated as follows,

Percentage of inhibition $(\%)=$

(OD of Control- OD of Sample/ OD of Control) X 100

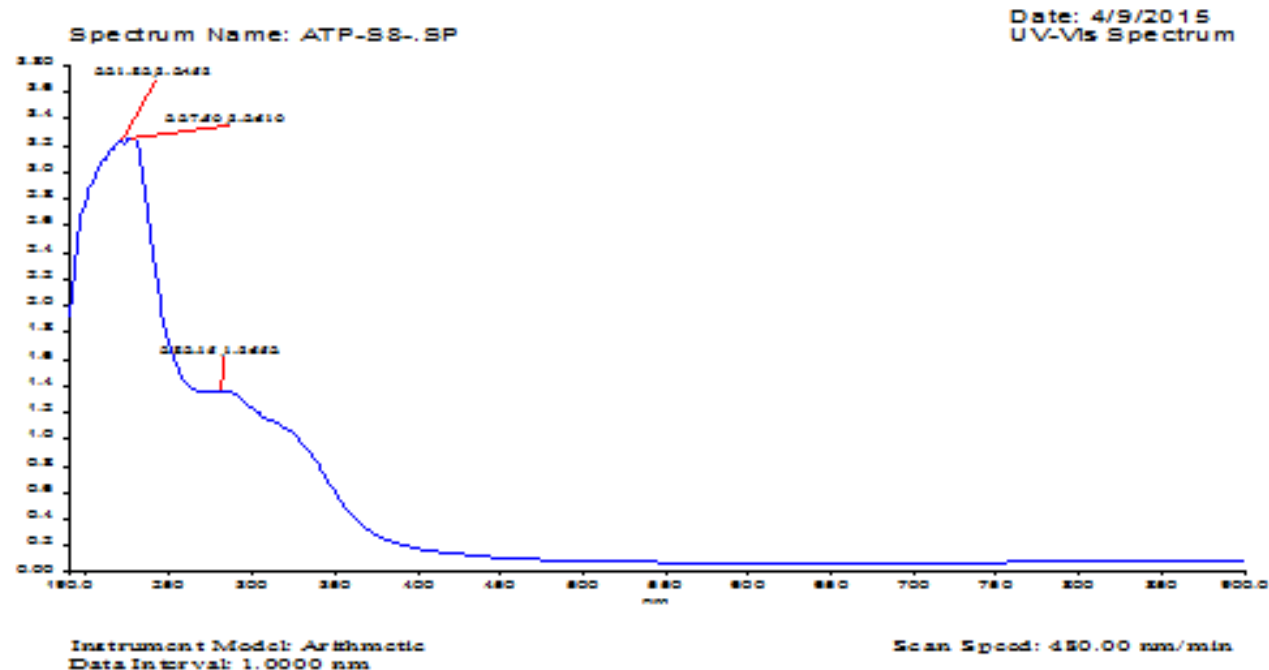

Figure 2: UV-Visible spectrum of synthesized silver nanoparticles using leaf extract of Ocimum basilicum.

\section{Results}

\section{UV-Visible Spectroscopy Analysis}

UV-Vis spectroscopy analysis of silver nanoparticles synthesized using Ocimum basilicum leaf extract shows the absorption band at $227.50 \mathrm{~nm}$, which indicates the presence of poly-unsaturated and aromatic compound (Isoquinoline). (Advanced strategies in food analysis , UV-VIS spectrometry by Richard Koplík)

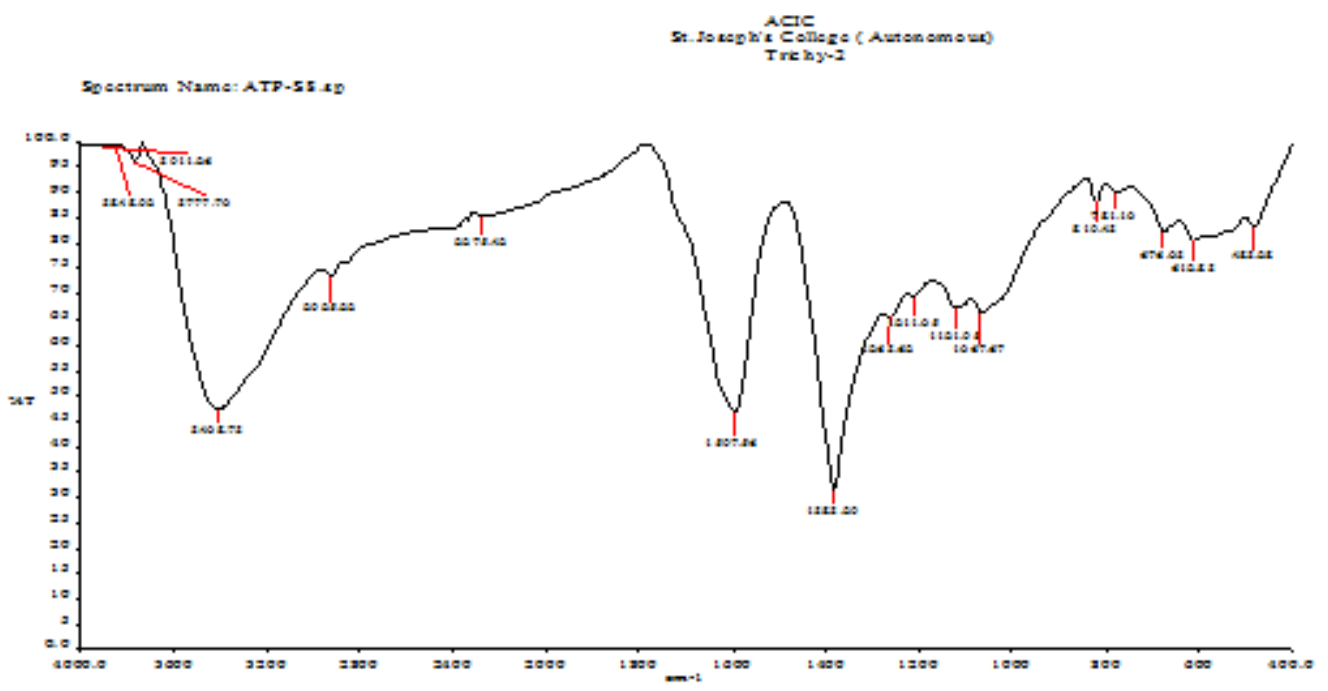

Figure 3: FT-IR spectrum of synthesized silver nanoparticles using leaf extract of Ocimum basilicum.

FT-IR Measurement

The related functional groups of Silver nanoparticles using Ocimum basilicum leaf extract were identified using the peak assignments. A strong peak at $3911.26 \mathrm{~cm}^{-1}, 3848.92$ $\mathrm{cm}^{-1}$ and $3777.70 \mathrm{~cm}^{-1}$ was assigned to the $\mathrm{OH}$ stretching in Phenol group, The sharp and bend peak at $3408.73 \mathrm{~cm}^{-1}$ was 


\section{International Journal of Science and Research (IJSR) \\ ISSN (Online): 2319-7064 \\ Index Copernicus Value (2013): 6.14 | Impact Factor (2014): 5.611}

assigned to $\mathrm{OH}$,H-bonded alcohol and phenols, The medium peak at $2925.22 \mathrm{~cm}^{-1}$ was assigned to $\mathrm{OH}$ stretching in carboxylic acid, wide peak at $2275.42 \mathrm{~cm}^{-1}$ was assigned to $-\mathrm{C}$ (triple bond) $\mathrm{C}-\mathrm{H}$ stretching in alkenes group, The medium peak at $1597.56 \mathrm{~cm}^{-1} \mathrm{~N}-\mathrm{H}$ bend stretching may be present primary amides group, The broad peak at 1383.29 $\mathrm{cm}^{-1}$ was assigned to $\mathrm{OH}$ stretching in alcohol and phenol group, The strong peak at $1263.62 \mathrm{~cm}^{-1}$ was assigned to C-N stretching in aromatic amines group, The strong peak at $1211.05 \mathrm{~cm}^{-1}$ was assigned to $\mathrm{C}-0$ stretching in alcohol and carboxylic acids, ester and ether, The medium peak at
$1121.95 \mathrm{~cm}^{-1}$ and $1067 \mathrm{~cm}^{-1}$ was assigned to $\mathrm{C}-\mathrm{N}$ stretching in aliphatic group, The strong peak at $819.43 \mathrm{~cm}^{-1}$ and 781.10 $\mathrm{cm}^{-1}$ was assigned to $\mathrm{N}-\mathrm{H}$ or $\mathrm{C}-\mathrm{H}$ stretching in primary and secondary amines or aromatics group, The medium peak at $676.03 \mathrm{~cm}^{-1}$ was assigned to $\mathrm{C}-\mathrm{Cl}$ stretching of alkyl halides, The medium peak at 612.83 and $483.28 \mathrm{~cm}^{-1}$ was assigned to $-\mathrm{C}$ (triple bond) $\mathrm{C}-\mathrm{H}$ and $\mathrm{C}-\mathrm{H}$ bend stretching in alkenes groups were observed.

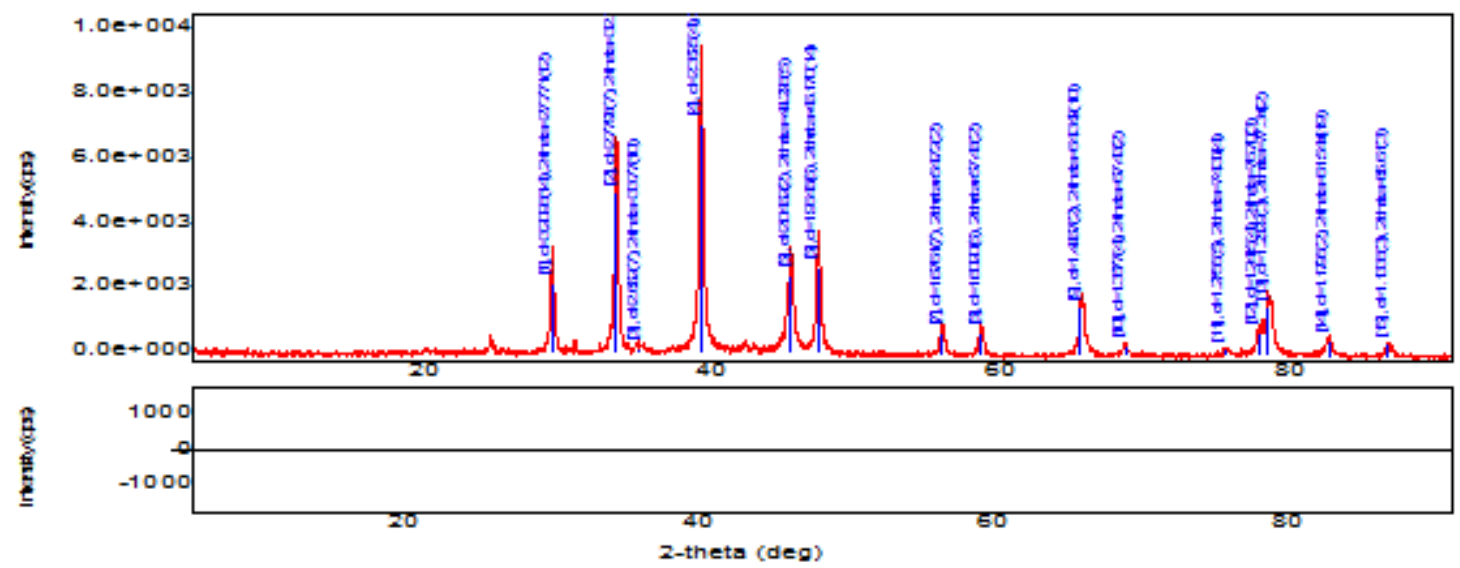

Figure 4: XRD spectrum of synthesized silver nanoparticles using leaf extract of Ocimum basilicum.

\section{XRD Measurement}

\section{Determination of crystalline size}

Average crystallite size of silver was calculated using the Scherrer's formula,

$\mathrm{D}=\mathrm{k} \lambda / \beta \cos \theta$

D- Average crystallite size, K- Constant: $\lambda$ - $\mathrm{X}$ - ray Wavelength, $\beta$ - Angular FWHM of the XRD peak at the diffraction angle, $\theta$ - Diffraction angle.

By using Scherrer's formula in XRD data, the size of the particle is approximately found to be $14.6 \mathrm{~nm}$.
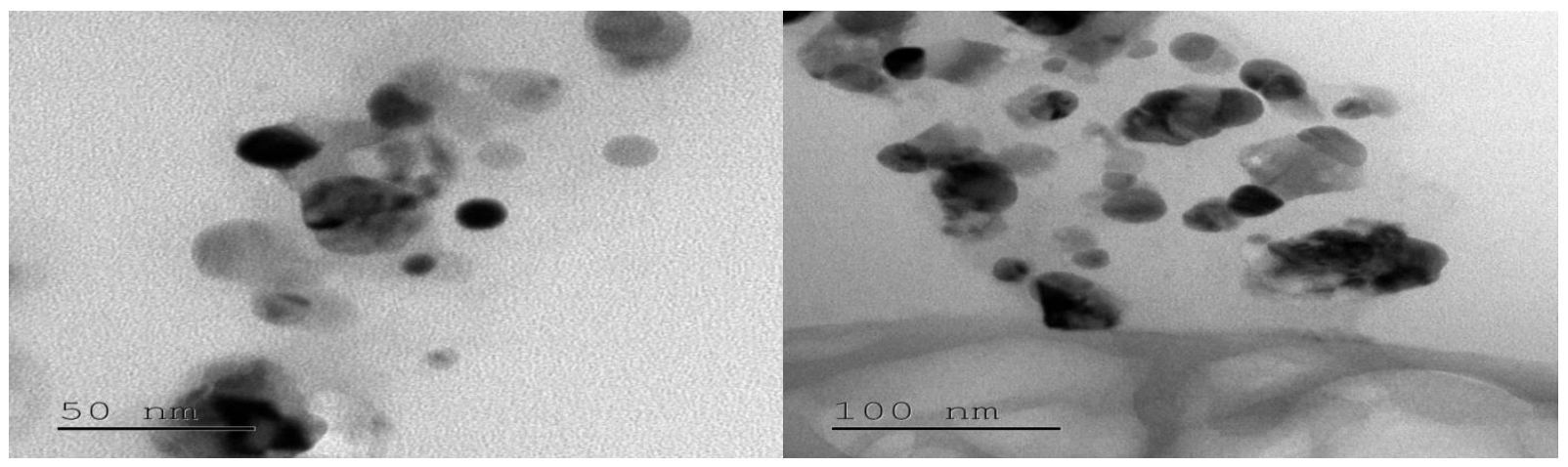

\section{TEM Analysis}

Figure 5: TEM image of synthesized silver nanoparticles using leaf extract of Ocimum basilicum
The figure shows the TEM image obtained by the reaction of Ocimum basilicum leaf extract and $0.1 \mathrm{~N}$ silver nitrate solution separately. The size of Ag-NPs using Ocimum basilicum leaf extract was found to be $13.84 \mathrm{~nm}$.

\section{ANTI-INFLAMMATORY ACTIVITY}

Anti-inflammatory study like human red blood cell (HRBC), membrane stabilization and inhibition of albumin denaturation indicated that anti-inflammatory activity .The medical use of Ocimum basilicum has a good antiinflammatory activity, As the concentration of the sample increases, the percentage of inhibition also increases.
Table 1: Anti-inflammatory activity of human red blood cell (HRBC) by using AgNPs of Ocimum basilicum leaf extract

\begin{tabular}{|c|c|c|}
\hline \multirow{2}{*}{ S.No } & $\begin{array}{c}\text { Concentration } \\
(\mu \mathrm{g} / \mathrm{ml})\end{array}$ & \begin{tabular}{c} 
\% of Inhibition \\
\cline { 3 - 3 }
\end{tabular} \\
\cline { 3 - 3 } & 100 & $28.20 \pm 0.18$ \\
\hline 2 & 200 & $33.41 \pm 0.41$ \\
\hline 3 & 400 & $40.72 \pm 0.39$ \\
\hline 4 & 600 & $42.81 \pm 0.17$ \\
\hline 5 & 800 & $47.39 \pm 0.32$ \\
\hline
\end{tabular}




\section{International Journal of Science and Research (IJSR) \\ ISSN (Online): 2319-7064}

Index Copernicus Value (2013): 6.14 | Impact Factor (2014): 5.611

\section{HRBC membrane Stabilization method}

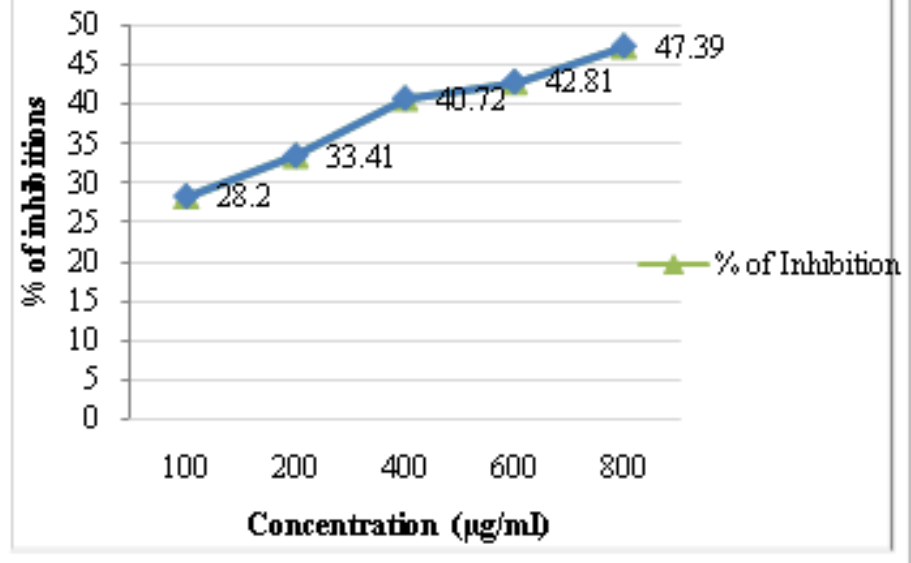

Figure 6: Graphical representation of Anti-inflammatory activity of human red blood cell (HRBC) by using AgNPs of Ocimum basilicum leaf extract

Table 2: Anti-inflammatory activity of Albumin denaturation method by using AgNPs of Ocimum basilicum leaf extract

\begin{tabular}{|c|c|c|}
\hline S. No & $\begin{array}{c}\text { Concentration } \\
(\mu \mathrm{g} / \mathrm{ml})\end{array}$ & \begin{tabular}{c} 
\% of Inhibition \\
\cline { 3 - 3 }
\end{tabular} \\
\hline 1 & 100 & $27.16 \pm 0.73$ \\
\hline 2 & 200 & $32.73 \pm 0.57$ \\
\hline 3 & 400 & $38.19 \pm 0.82$ \\
\hline 4 & 600 & $41.45 \pm 0.41$ \\
\hline 5 & 800 & $46.32 \pm 0.54$ \\
\hline
\end{tabular}

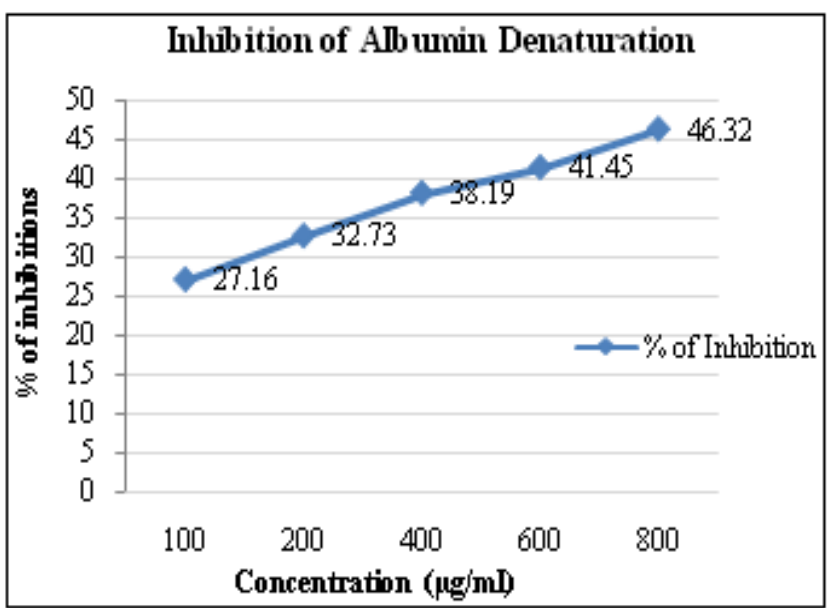

Figure 7: Graphical representation of Anti-inflammatory activity of Albumin denaturation method by using AgNPs of Ocimum basilicum leaf extract

\section{Discussion}

The Silver nanoparticles formed were quite stable in the solution. SEM analysis confirmed the range of particle size between 22 to $42 \mathrm{~nm}$. The carbohydrates, flavanoids and poly phenols constituents present in leaf extract act as the surface active stabilizing molecules for the synthesis of Silver nanoparticles. The method was unique and cost effective. Still more clinical trials are needed to support its therapeutic uses ${ }^{27}$. The FTIR peak corresponds to the presence of $\mathrm{C}-\mathrm{H}$ vibration of the aromatic ring and the stretch vibration of $\mathrm{C}-\mathrm{O}$ indicates carbonyl group and flavonoids. SEM analysis of the synthesized Silver nanoparticles are clearly distinguishable and the particles are measured $<100 \mathrm{~nm}$ in size. The EDX spectrum shows the purity of the material. Synthesis is conventional and found to be efficient in terms of reaction time as well as cost is effective $^{28}$. The SEM results reveals that the average size of silver nanoparticles synthesized from $O B$ extract was found as spherical shape and $120 \mathrm{~nm}$ in size ${ }^{29}$.

Traditionally, Ocimum basilicum has been used for its antiinflammatory activity. Here, the effect of $\mathrm{O}$. basilicum ethanol extract was evaluated on carrageenan induced paw edema in male Wistar rats. The ethanol extract of $\mathrm{O}$. basilicum (basil) exerts a potent action against inflammation and confirm that the extract contains an effective antiinflammatory substance(s). Our results support the claim of traditional use of $\mathrm{O}$. basilicum for the treatment of inflammation. Future studies may focus on the exact mechanism(s) responsible for its anti-inflammatory effect and identify the active compound(s) ${ }^{30}$.

\section{Conclusion}

In the present investigation, it was noted that silver nanoparticles synthesized using aqueous plant extract exhibited reddish brown colour in aqueous solution due to excitation of Surface Plasmon Vibrations. The UV absorption spectra of biosynthesis nanoparticles in all methods gave absorption maximum at $227.50 \mathrm{~nm}$, which indicates the presences of poly-unsaturated aromatic compound (Isoquinoline). Silver nanoparticles are synthesized using aqueous Ocimum basilicum leaf extract by microwave technique. The TEM and XRD results reveals that the average size of silver nanoparticles synthesized from Ocimum basilicum leaf extract was found to be13.84 nm and $14.6 \mathrm{~nm}$ respectively. The bio-reduction of aqueous silver ions by the plant extract of Ocimum basilicum leaf extract is a good source for green environment approach towards the synthesis of silver nanoparticles and has many advantages such as, comfort with which the process can be scaled up, economic feasibility, etc., 


\section{International Journal of Science and Research (IJSR) \\ ISSN (Online): 2319-7064}

Index Copernicus Value (2013): 6.14 | Impact Factor (2014): 5.611

\section{References}

[1] Buzea C., Pacheco I.I., Robbie K., Nanomaterials and nanoparticles: Sources and toxicity, Biointerphases, 2007, 2, MR17-MR71.

[2] De Feo, V., Senatore, F. 1993. Medicinal plants and phytotherapy in the Amalfitan Coast, Salerno Province, Campania, Southern Italy. Journal of Ethnopharmacology 39, 39, 51.

[3] Elumalai EK, Prasad T N V K, Hemachandran J, Viviyan Therasa S, Thirumalai $T$, David E, Extracellular synthesis of silver nanoparticles using leaves of Euphorbia hirta and their antibacterial activities. J. Pharm. Sci. \&Res, 2010; 2(9): 549-554.

[4] Mazur, M. Electrochemically Prepared Silver Nanoflakes and Nanowires. Electrochemistry Communications, 2004; 6: 400-403.

[5] Simon, J E., Morales, M. R., Phippen, W. B, Vieira, R. $\mathrm{F}$ and Hao, Z. A source of aroma compounds and a popular culinary and ornamental herb. ASHS Press, Alexandria. 1999; 499-505.

[6] Wannissorn, B., Jarikasem, S., Siriwangchai, T and Thubthimtheb, S. Antibacterial properties of essential oils from Thai medicinal plants. Fitoterapii, 2006; 76 : 233-236.

[7] Politeo, O., Jukic, $M$ and Milos, M . Chemical composition and antioxidant capacity of free volatile aglycones from basil (Ocimum basilicum L.) compared with its essential oil. Food Chemical, 2007; 101:379385.

[8] Bravo, E., Amrani, S., Aziz, M., Harnafi, H and Napolitano, M. 2008. Ocimum basilicum ethanolic extract decreases cholesterol synthesis and lipid accumulation in human macrophages, Fitoterapia, 2008; 79: 515-523.

[9] Ip, M., Lui, S. L., Poon, N. K. M., Lung, I and Burdo, A. Antimicrobial activities of silver dressings: an in vitro comparison. Journal of Medical Microbiology. 2006; 55: 59-63.

[10]Esumi K, Kameo A, Suzuki A, Torigoe K. "Preparation of gold nanoparticles in formamide and N,N-dimethyl formamide in the presence of poly(amidoamine) dendrimers with surface methyl ester groups". Colloids and Surf A: Physicochem. Eng. Aspects. 189(1-3), pp. 155-161, 2001

[11] Prathna TC, Mathew L, Chandrasekaran N, Raichur AM, Mukherjee A. "Biomimetic Synthesis of Nanoparticles: Science, Technology \& Applicability", Edited A. Mukherjee, InTech Publishers, Croatia, pp. 120, 2010 .

[12] Mubarak Ali D, Sasikala M, Gunasekaran M, Thajuddin. "Biosynthesis and Characterization of silver nanoparticles using marine cyanobacterium, Oscillatoriawillei NTDM01". Dig. J.Nanomater. Bios. 6(2), pp. 385-390, 2011.

[13]U.Viplav Prasad, B Syama sunder G.Anuradha, J.Sreekanthkumar "Chemical examination of Morindapubescens Ver. pubescens and Isolation of crystalline constituents" Proceedings of Chemistry of Phytopotentials: Health, Energy\& Environmental Perspective, pp. $73-76,2011$.

[14] Tsang, C, Caps, V, Paraskevas, I, Chadwick, D, Thompsett, D: "Magnetically separable, carbon- supported nanocrystals for the manufacture of fine chemical". Angew Chem 116, pp. 5763-5767, 2004.

[15] Baptista, PV: "Cancer nanotechnology - prospects for cancer diagnostics and therapy". Curr Canc Ther Rev 5(2), pp. 80-88, 2009

[16] Huang, CC, Yang, Z, Lee, KH, Chang, HT: "Synthesis of highly fluorescent gold nanoparticles for sensing mercury (II)". Angew Chem Int Ed 46, pp.6824-6828, 2007.

[17] Jain, PK, Lee, KS, El-Sayed, IH, El-Sayed, MA: "Calculated absorption and scattering properties of gold nanoparticles of different size, shape, and composition: applications in biological imaging and biomedicine". J PhysChem B 110, pp. 7238-7248, 2006.

[18] Murphy, CJ, Sau, TK, Gole, AM, Orendorff, CJ, Gao, J, Gou, L, Hunyadi, SE, Li, T: "Anisotropic metal nanoparticles: synthesis, assembly, and optical applications". J PhysChem B 109, pp.13857-13870, 2005.

[19] Chidambaram Jayaseelan, et al, "Acaricidal efficacy of synthesized silver nanoparticles using aqueous leaf extract of Ocimum canum against Hyalommaanatolicumanatolicum and Hyalommamarginatumisaaci (Acari:Ixodidae)" Parasitology research, 11(3), pp.1369-78, 2012.

[20] McClatchey, W. (1996) The ethnopharmacopoeia of Rotuma. J. Ethnopharmacol., 50, 147-156.

[21] Pushpangadan, G. and Sobti, S. N. (1977) Medici-nal properties of Ocimum (Tulsi) species and some recent investigation of their efficacy. Indian Drugs, 14, 207.

[22] Keita, S. M., Vincent, C., Schmit, J., Arnason, J. T. and Belanger, A. (2001) Efficacy of essential oil of

[23] Ocimum basilicum L. and O. gratissimum L. appliedas an insecticidal fumigant and powder to control Callosobruchus maculates. J. Stored Prod. Res., 37, 339-349.

[24] Abas, F., Lajis, N. H., Israf, D. A., Khozirah, S. and Kalsom, Y. U. (2006) Antioxidant and nitric ox-ide inhibition activities of selected Malay traditional vegetables. Food Chem. Toxicol., 95, 566-573.

[25] Velazquez C, Calzada F, Torres J, Gonzalez F, Ceballos G. Antisecretory activity of plants used to treat gastrointestinal disorders in Mexico. J Ethnopharmacol2006;103:66-70.

[26] Rahimi R, Shams-Ardekani MR, Abdollahi M. A review of the efficacy of traditional Iranian medicine for inflammatory bowel disease: World JGastroenterol2010;16:4504-4514.

[27] Anuradha.G, B. SyamaSundar, J. Sreekanthkumar, M.V. Ramana, Synthesis and Characterization of Silver Nanoparticles from Ocimum basilicum L. var. thyrsiflorum, European Journal of Academic Essays 1(5): 5-9, 2014.

[28] Anuradha. G, B. Syama Sundar, M. V. Ramana, J. Sreekanthkumar and T. sujatha, Single step synthesis and characterization of Silver nanoparticles from Ocimum tenuiflorum L. Green and Purple, Volume 7, Issue 5 Ver. II. (May. 2014), PP 123-127

[29]E. Jayapriya and P. Lalitha, Synthesis of Silver Nanoparticles using Leaf Aqueous Extract of Ocimum basilicum (L.)Int.J.ChemTech Res.2013,5(6)

[30] Maryam Rameshrad, Ronak Salehian, Fatemeh Fathiazad, Sanaz Hamedeyazdan, Mehraveh Garjani, 


\section{International Journal of Science and Research (IJSR) \\ ISSN (Online): 2319-7064}

Index Copernicus Value (2013): 6.14 | Impact Factor (2014): 5.611

Nasrin Maleki-Dizaji Reza Vosooghi, The Effects of Ocimum Basilicum Ethanol Extract on Carrageenan Induced Paw Inflammation in Rats, Pharmaceutical Sciences, March 2015, 20, 149-156.

\section{Author Profile}

Dr. P. Sakthivel currently working as Associate Professor, Department of Physics, Urumu Dhanalakshmi College, Trichy, Tamilnadu, India. He is guiding Post graduates, M.Phil and Research scholars.

Mrs. P. Anitha currently working as Assistant Professor in Department of Physics at Roever College Of Engineering and Technology, Elambalur, Perambalur (D.T). Tamilnadu, India. 